\title{
Convención Americana sobre Derechos Humanos. Comentario Christian Steiner y Patricia Uribe (editores). Konrad Adenauer
Stiftung e.V., 2014, 1040 páginas.
}

I. La iniciativa.

1. Tengo el honor de presentar la mejor recopilación de la jurisprudencia emanada de la Corte IDH. Por supuesto que había notables trabajos hechos con anterioridad. En algunos casos, parciales, como la obra de Ventura Robles y Zovatto sobre la función consultiva de la Corte. También está el emblemático trabajo de Thomas Buergenthal, Robert Norris y Dinah Shelton sobre "La protección de los derechos humanos en las Américas", pasando por los trabajos comparativos de Héctor Gross Espiell sobre el análisis comparativo de las Convenciones europea y americana de derechos humanos. Todos ellos precursores de un texto como el que hoy nos toca reflexionar y que circula en diversas versiones desde el año pasado por todo el continente. Por citar un solo ejemplo, en la excelente recopilación de sentencias de Rubén Hernández Valle, hecha el 2011 para el Centro de Estudios Políticos y Constitucionales, se vuelca el texto a comentar 25 sentencias básicas de la Corte IDH y relativa a tres derechos fundamentales que contrastan con este texto completo, que cita sobre más de dos centenares de sentencias, informes y observaciones solo del Sistema Interamericano de Derechos Humanos, sin agregarle la enorme recopilación doctrinaria y jurisprudencial, mayoritariamente europea.

2. Bajo el trabajo de coordinación de Christian Steiner y de Patricia Uribe se convocó a un conjunto excepcional de juristas de vocación ius latinoamericanista. Por Chile, Cristián Correa y Claudio Nash, como exponentes de trayectorias académicas, jurídicas y de compromiso que no descubrimos ahora, sino que celebramos junto a ellos.

3. A su vez, por la región un equipo de profesores muy destacados, con mayor o menor impacto de sus trabajos en nuestro país, pero cuya trascendencia conocemos. Entre ellos, destacan Ferrer, Sagües, Beloff, Uprimny, Tojo, Casal, Dulitzky y Courtis, entre el listado de 30 autores, en fin, gratitud incompleta para los que no mencionamos.

4. Este libro ha sido auspiciado y financiado en su investigación por la Fundación Konrad Adenauer. Permítaseme una palabra para la acción de la Fundación y, en general, de la influencia alemana en el Derecho. Este libro ha tenido su propia trayectoria para llegar a puerto, la cual no siempre ha sido fácil, como se describe en la contratapa de un proyecto que se inició en diciembre de 2011. 
Las incomprensiones que la ciencia despliega en la esfera de las relaciones sociales y humanas son más complejas que aquellas de las llamadas "ciencias duras". Sin embargo, no todo en el derecho es así. La acción académica y jurisdiccional tiene que avanzar hasta el estadio que asumen los juristas respecto de las cuestiones penales. Cuando hoy se cita a Roxin, Jacobs en un diálogo donde antes estuvo Welzel, ningún penalista entiende que está haciendo un argumento extravagante y excéntrico, carente de racionalidad. Justamente todo lo contrario; hemos aprendido de que esas categorías de racionalidad, distinción y excelsa pulcritud intelectual tienen por objeto identificar cómo se protegen los bienes jurídicos esenciales para la vida en comunidad. ¿ Por qué no en el Derecho Público? De una tradición que legó a Jellinek, a Heller, a Leibholz, hasta autores como Hesse, Stern, Alexy, Benda, Schneider, Haberle, Denniger o Bockenforde en el ámbito constitucional, para citar a aquellos que han configurado parte de los debates sobre la democracia constitucional. La aceptabilidad argumental alcanzada en el ámbito penal es un bien deseable para todos los demás ámbitos del derecho, con las dificultades que tiene hacerlo en un contexto tan simbólico como la garantía y promoción de los derechos humanos en nuestra región.

5. Para terminar esta introducción, resulta necesario reconocer el emblemático Programa de Estado de Derecho para América Latina, que demuestra el mejor tipo de alianza europea - americana en la construcción de marcos civilizatorios en democracia. Por lo demás, la Fundación Konrad Adenauer colabora en una de las tareas más difíciles de la región: sostener el cumplimiento de la ley y los derechos fundamentales, asediados por la inseguridad, el crimen, el narcotráfico, los conflictos internos, y la corrupción, avanzando en la construcción de institucionalidad como bienes públicos inmateriales de nuestras democracias. En Chile lo hacen colaborando con plena transparencia desde 1962 y hoy con programas muy exitosos en nuestra esfera, participando con el Poder Judicial y nuestro Tribunal. Vaya nuestro reconocimiento a la tarea de la Fundación representada en esta oportunidad por su Director en Chile, Sr. Holger Haibach y por el cerebro y alma de esta obra colectiva: Christian Steiner.

\section{El libro.}

6. El libro tiene en esta versión chilena 1.040 páginas, que se extienden a un Comentario circunstanciado de cada uno de los 82 artículos de la Convención Americana sobre Derechos Humanos. Es un texto con un índice temático de 440 entradas principales que guían con profundidad los contenidos desplegados a lo largo de este trabajo monumental. Asimismo, es un comentario circunstanciado cada uno de los 82 artículos de la CADH y su preámbulo, bajo una fórmula de 43 monografías que incluye una Sección Especial Final sobre Pueblos Indígenas, la Corte IDH, el Fondo y Reparaciones.

Las dimensiones dogmáticas de los derechos y deberes están descritas mediante un examen exhaustivo artículo por artículo, como resulta natural de la riqueza de la jurisprudencia de la Corte. En cambio, los artículos relativos a procedimientos, a la Comisión Interamericana, la Corte misma y las disposiciones relativas al Tratado, tienen un tratamiento agrupado.

Asimismo, por cuestiones editoriales del cierre de la edición alcanza a constatar relevantes sentencias de la Corte IDH que no alcanza a comentar. Entre ellas, los famosos casos de Sarayaku con Ecuador, Artavia Murillo con Costa Rica, Masacres de El Mozote con El Salvador, Caso Mémoli versus Argentina, Caso 
Corte Suprema contra Ecuador, Caso J contra Perú, Caso Brewer Carias contra Venezuela y Caso Norín Catrimán contra Chile, entre otros.

\section{III. ¿Por qué el TC publicó este texto y lo difundió?}

Esta publicación, no su contenido por cierto, es una decisión colegiada del TC que se manifiesta en actos tan sencillos como claros. Viene precedido de un Prólogo de la anterior Presidenta del TC, Ministra Marisol Peña; está impreso bajo el período del Presidente Carlos Carmona, quien ha solicitado a uno de los Ministros para que realice esta presentación. Es el ejercicio continuo de un Tribunal que actúa bajo una sola voz, aunque habiten distintos criterios en su seno. Pero más relevante que esto, es el hecho de que esta decisión colegiada se enmarca en el artículo $5^{\circ}$ de la Constitución. Es también parte de nuestro deber, respetar y promover los derechos reconocidos en los tratados internacionales, máxime si este funda el Sistema Interamericano de Derechos Humanos.

Adicionalmente, porque los tratados de derechos humanos son el reflejo de un derecho vivo que cristaliza sus contenidos abstractos en el despliegue concreto de los dilemas que se presentan primero a la Comisión y en menor medida ante la Corte.

Por lo tanto, no se trata solo de conocer el contenido de los tratados. Hoy eso no es suficiente sin un examen pormenorizado de la jurisprudencia de la Corte.

Y aunque parezca de perogrullo, un libro de esta naturaleza tiene un sentido pedagógico profundo, por lo mismo, habrá que decir una cosa tan evidente como relevante. La CADH y la jurisprudencia de la Corte IDH no es derecho extranjero. No es una cita de aquellas muchas que se pueden encontrar en la "boutique jurídica de Internet". Es derecho integrado al ordenamiento y precedido del deber de respeto, esto es, de la obligación estatal de no violar, directa ni indirectamente, por acción u omisión, los derechos y libertades reconocidos en la Convención”" ${ }^{1}$ Y este deber de respeto exige en la Constitución, su "promoción", esto es, el actuar vigoroso que permita siempre identificar y remover los obstáculos que impiden el libre ejercicio de los derechos fundamentales contenidos en éste y otros instrumentos. Por lo tanto, cuando se cita una opinión extranjera se podría estar frente a un ejercicio de erudición (si es que ésta es acertada, pertinente, completa, etc.) pero si nos referimos a la CADH y a su jurisprudencia no es más que el ejercicio de un deber al que los jueces estamos obligados.

$\mathrm{LaCADH}$ es nuestro derecho porque es el reflejo de una garantía jurisdiccional que, a partir de nuestro ordenamiento constitucional, no es sino la fase jurisdiccional en la esfera de las garantías internacionales a las cuales cada chileno tiene derecho. Lo anterior, es muy emblemático del papel que juega el ordenamiento nacional en relación con el conjunto del Sistema Interamericano de Derechos Humanos. Chile, como cualquier país integrante del Sistema, es el eslabón natural para el desarrollo, despliegue y resolución de los conflictos sobre derechos en el marco de un sistema multinivel. El agotamiento de los recursos internos como paradigma procesal para recurrir a la Comisión no es la resignación frente a la injusticia, sino que es el eslabón que la compromete a obtener el máximo nivel de protección al interior de cada país. La garantía jurisdiccional supranacional es una forma de protección tardía, complementaria y de

Mac Gregor y Pelayo Moller, p. 47 
ultima ratio. Por lo mismo, las sentencias de la Corte IDH que se adoptan formalmente "contra o vs." el país, no es la medida para verificar una particular animadversión o una derrota desde quién tiene la última palabra. No está en juego ni la soberanía, ni el prestigio del país detrás de una de estas decisiones. Lo que sí demuestra nuestro sistema interamericano respecto de los que lo han aceptado en plenitud es que este representa el estándar sobre el cual deseamos construir nuestra convivencia. Los casos que se salen de tal estándar no constituyen un demérito del país, como no lo son las Sentencias del TEDH que condenan a un determinado país europeo, salvo que se hagan de manera sistemática y frecuente, cuyo no es el caso.

Este libro se encuentra en el punto en que se encuentran la doctrina y la jurisprudencia interamericana y nacional en un momento determinado, siendo su difusión un ejercicio de polinización sobre nuestros operadores jurídicos para que fertilice con mayor fuerza la cultura de los derechos humanos en la región y en el país.

Otra razón que tuvo a la vista el Tribunal Constitucional son los 35 años que cumplió la propia Corte desde que se estableciera, como de soslayo, en el segundo sistema regional de protección de derechos humanos. La fuerza pionera de la Declaración Americana de Derechos y Deberes del Hombre de 1948 y la propia adopción de la Convención configuraron un hecho internacional que devino en la creación de la Corte, en un contexto altamente desfavorable para los derechos humanos en la región.

Como dice un autor, esta Convención vivió bajo los efectos de la Cenicienta, con mayoritarios gobiernos de facto, que despertó de un letargo que le permitió subsistir y ser lo fuerte, relevante y señera que hoy aparece ante la comunidad jurídica de la Región.

Simplemente no es posible desconocer la jurisprudencia de la Corte IDH porque en ella se refleja buena parte de las conquistas de estándares internacionales que son válidos para el Derecho interno. Por tanto, se ha vuelto para un juez un elemento de inexcusable conocimiento y para los operadores jurídicos una herramienta poderosa en la defensa y vigencia del Estado de Derecho. En síntesis, se ha hecho cada vez más frecuente el sostener la existencia de una suerte de Corpus Iuris Commune para América Latina ${ }^{2}$. Este derecho, sin una accesibilidad a fuentes explicativas y razonadas de los fallos de la Corte, es un debilitamiento de la construcción de un lenguaje común sobre el cual se va entendiendo nuestra comunidad jurídica en la región y respecto del parámetro que nos divide para enjuiciar un estado de comportamiento acorde a estas garantías básicas. Por tanto, el ejercicio de publicar este texto no es sino la manifestación del cumplimiento del deber de promover los derechos humanos propios de la reivindicación de la dignidad humana, como deber estatal interno de un órgano del Estado como lo es el Tribunal Constitucional de Chile.

\section{Desafíos jurisprudenciales de esta publicación.}

Este enorme trabajo es muy difícil de comentar por lo extenso y por los variadísimos temas que aborda. Por lo tanto, afrontaré este Comentario como un desafío a las vías interpretativas de nuestra jurisprudencia a partir de este examen del Derecho vivo que representa este libro. 
En primer lugar, hay que advertir que el texto, como es propio de la tradición de derechos humanos, no es solamente un trabajo descriptivo de la jurisprudencia de la Corte, sino que tiene enfoques críticos en determinadas materias y está lejos de ser contemplativo con el trabajo de la propia Corte. Tal son los ejemplos de los capítulos del propio Claudio Nash sobre el derecho a la integridad personal, de Alejandro Gonza sobre el derecho a la propiedad privada, o el de Christian Courtis sobre la cláusula de desarrollo progresivo que explica el artículo 26 de la CADH sobre los DESC, por citar algunos ejemplos. Por tanto, no es un ejercicio de propaganda, sino que es un examen jurisprudencial del más alto nivel. Y lo es por los temas que plantea para la agenda y promoción de derechos en el ámbito nacional. Partamos, justamente, por acá nuestros comentarios de fondo. Por continuar con el ejemplo, la dificultad que plantea Courtis tiene que ver con el diseño institucional de la CADH y del sistema interamericano de DD.HH. Resulta evidente que el que está en mejor posición de tener una satisfacción jurisdiccional más evolutiva, expansiva y certera de los DESC es el propio juez nacional, en la medida que sus propios ordenamientos sugieran modalidades de una arquitectura institucional superior. El punto es que la construcción del Ius Constitucionale Commune exigiría una fórmula que comience a rastrear y recopilar la mejor jurisprudencia sobre derechos sociales de los tribunales y cortes constitucionales de la región. La Fundación, al sacar este libro, tiene la tarea pendiente de andar el camino en un sentido contrario y desde un catálogo común de derechos recopilar la mejor jurisprudencia local sobre los mismos tópicos.

En segundo lugar, este libro recopila una suerte de proceso en ascenso de la Corte IDH. Es evidente que nos encontramos frente a una jurisprudencia madura, a una institución consolidada y a un método tan persuasivo como profesional. Y en esta fase de ascenso la sana ambición de la Corte la ha llevado a utilizar en su jurisprudencia fórmulas "prestadas" del diálogo constitucional que le dan un vigor y una forma de encanto especial. Hay que advertir que esto lo dice un constitucionalista que tiene el máximo respeto por el Derecho Internacional. Pero parece claro que hablar del "efecto útil" de los Tratados no es lo mismo que utilizar la expresión "fuerza expansiva". En uno nos suena el denostado "utilitarismo" y en el otro resuena el eco de la progresión de los principios. Vaya diferencia. El lenguaje reconstruye el dilema y ahora se nos instala con el "control de convencionalidad" vis a vis "control de constitucionalidad", cuya explicación trasunta una fórmula interpeladora. Se trata de un "control difuso" no a la americana sino que a lo interamericana. Ya el juez no es un juez nacional sino que por obra de este control es un juez interamericano, porque opera para la mayor vigencia de la $\mathrm{CADH}$ y tiene herramientas poderosas en su mano, mediante la inaplicación por inconvencionalidad del Derecho interno.

En tercer lugar, si bien el libro está centrado en la jurisprudencia de la Corte IDH, es evidente que su objeto preferente es el examen de la aplicación de la $\mathrm{CADH}$, siendo el trabajo de la Comisión Interamericana de Derechos Humanos una herramienta esencial de su explicación. Es así como los Informes de esta son parte sustantiva del análisis que tienen algunos artículos de la $\mathrm{CADH}$ que no siempre llegan a la instancia propiamente de la Corte. Este libro, por supuesto, da cuenta de esta labor de la Comisión, sea por sus informes como por sus trabajos preparatorios de la Convención, que es fundamental, por ejemplo, para entender el artículo 4, sobre el derecho a la vida, en lo tocante al complejo punto de delimitar la expresión (Este derecho estará protegido por la ley, en general, desde el momento de la concepción) en el trabajo de Carlos Ayala y María Daniela Rivero. O para especificar la frontera que divide la esclavitud de la servidumbre, ambas prohibidas por el artículo $6^{\circ}$ de la $\mathrm{CADH}$, en el texto de Federico Andreu. De la misma manera, es fundamental el escrito de Marco Huaco, que da cuenta de las estrategias jurídicas de la Comisión para ampliar la libertad de conciencia y de religión a aquellos países que no han suscrito 
la CADH o que habiéndola suscrito no han aceptado la jurisdicción de la Corte, utilizando para ello la Declaración Americana de Derechos y Deberes del Hombre. En esa perspectiva abarca la importantísima cuestión de la titularidad limitada de las personas jurídicas en los procedimientos ante la Corte, ampliando derechos a las agrupaciones religiosas o a los pueblos indígenas como manifestaciones de un derecho de manifestación colectiva. $\mathrm{O}$ en el artículo 22 sobre el derecho a la circulación y residencia que ha tenido pronunciamientos acerca de expulsiones colectivas de extranjeros así, como sobre el principio de no devolución en casos de ingreso irregular al Estado de otro país (en el texto de Rodrigo Urpimny y Luz María Sánchez).

En cuarto término, me detendré en el alcance de la textura abierta de la competencia de la Corte. La competencia de la Corte IDH en relación con la materia se refiere al mandato del artículo 63.2 de la CADH que dispone cuáles son las normas de derecho internacional que le compete aplicar a la Corte IDH en su resolución de casos. Parecería que estuviera limitada por el contenido del propio Tratado. Sin embargo, la Corte IDH ha ido ampliando al uso de otros tratados internacionales de derechos humanos desde la decisión del caso Villagrán Morales en 1999.

Con ello, aplica todo el corpus iuris internacional incluidos los tres tratados interamericanos que le otorgan competencia expresa (el Protocolo de San Salvador, la Convención Belem do Pará y la Convención Interamericana sobre Desaparición Forzada de Personas. Asimismo, resulta evidente que se extiende a la Convención Interamericana sobre Prevención y Sanción de la Tortura. Resulta natural que está dentro de su competencia la aplicación de la Declaración de Derechos del Hombre y del Ciudadano, que se deduce del artículo 29 de la CADH como parámetro en materia de justiciabilidad de los DESC. De otra manera implícitamente ha ido citando la jurisprudencia del TEDH en mayor medida que esta cita a la Corte IDH. No obstante, parte del reconocimiento del prestigio de la Corte IDH se encuentra en los ejemplos en que aparece citado. Por lo tanto, como diría Burgorgue-Larsen la Corte IDH aplica generosamente técnicas abiertas de interpretación ${ }^{3}$ para adaptar todo el DIDDHH a sus soluciones sea del sistema universal de los DD.HH., como los Pactos, sea las delimitaciones y observaciones generales de la Comisión de Derechos Humanos de la ONU, sea la propia doctrina como elemento auxiliar y propio de un tipo de soft law. Este derecho exclusivo de la Corte IDH. La propia existencia de una cláusula puente en el artículo 5.2 de la CPR es una invitación a la integración con textura abierta de los estándares internacionales para la solución de casos nacionales en un esquema de control de constitucionalidad, y no de solo convencionalidad.

En quinto lugar, si el marco de una textura interpretativa abierta y la estructura puente del artículo $5^{\circ}$ de la Constitución nos invitan a reflexionar sobre el pluralismo normativo de fuentes estatales. El Pluralismo normativo es un hecho en nuestro actual estadio de desarrollo jurídico.

La noción de un centro de impulsión del derecho con estructuras coherentes, racionales y unitarias es una cuestión superada en los modelos de Derecho del siglo XXI.

Si nuestro Tribunal Constitucional ha reconocido el valor como fuente creadora de derecho incluso en normas técnicas propias de necesidades tecnológicas y científicas, con una mayor razón ha de ponderar la fuente jurídica emanada de los Tratados Internacionales acordados por Estados y ratificados por los Congresos.

3 Laurence Burgorgue-Larsen, "Ius constitutionale commune en América Latina 
Esa fuente de derecho, en el ámbito del Derecho Internacional de los Derechos Humanos, es una fuente principal de las obligaciones estatales que de conformidad con la Convención de Viena sobre el Derecho de los Tratados debe interpretarse de buena fe, integral y contextualmente con todos sus contenidos, preámbulos y anexos.

Esta fuente principal viene acompañada de los medios auxiliares para la determinación del derecho que da cuenta este libro, tanto por las decisiones judiciales de la Corte que comprende, como por la doctrina de los autores que la sintetizan.

El pluralismo normativo exige más de los juristas y de los jueces. Para quienes sienten temor por la aparente insegurización que genera esta diversidad de fuentes, la única manera de cerrar la brecha es estudiando profundamente cómo interpretarlas con coherencia. El rechazo frontal al Derecho Internacional de los Derechos Humanos no resiste análisis y este texto será un buen referente por un tiempo, hasta que sea superado por otros trabajos intelectuales que aporten tanto desde la jurisprudencia como desde la doctrina. Negar la evidencia, es negar la perspectiva del aporte desde la interpretación nacional, tanto desde la justicia como desde la doctrina.

El pluralismo normativo parte del reconocimiento que en los sistemas multinivel de protección de derechos humanos, el que habitualmente dará la primera, mejor y más consistente solución será el propio sistema nacional o local de derecho.

El pluralismo normativo no es neoconstitucionalismo ni una reducción de los exigentes requisitos de las teorías jurídicas. Es simplemente un punto de partida para que el intérprete le dé certeza al Derecho tomando en cuenta todas las fuentes. Desconocer las fuentes internacionales es un punto de partida más pobre y reduccionista en casos de derechos fundamentales.

El punto es que, si bien teóricamente sí es posible, en la práctica no todos los casos se resuelven o son propios de derechos fundamentales. La jurisprudencia local no está exigida al 100\% para citar la fuente internacional, siendo solo necesaria en los casos ineludibles.

El manejo de fuentes diversas ha llevado a un equívoco sobre el cual habrá que debatir nuevamente: ¿Cómo es recibido el Derecho Internacional de los Derechos Humanos en el orden interno?

En sexto lugar, hay que revisitar el dilema de la recepción del Derecho Internacional de los Derechos Humanos en el orden interno. Cuando la jurisprudencia de la Corte IDH era anecdótica, y tocaba escasamente casos nacionales, las tesis vigentes sobre la manera en que se producía la recepción del derecho interno eran reducidas a la élite que se dedicaba a estas materias. Hoy por hoy, con ocho sentencias contrarias al país, y con una jurisprudencia abundante que exige el conocimiento y, eventualmente, la aplicación de lo resuelto en los otros casos resulta un deber ineludible para el proceso formativo jurídico chileno.

El Tribunal Constitucional ha sido criticado en este tópico por la doctrina nacional, en circunstancias que la doctrina internacional ha ensayado fórmulas diversas para esa incorporación.

El punto de partida está en la regla de reconocimiento constitucional del Artículo $5^{\circ}$ inciso $2^{\circ}$ de la CPR. El Tribunal ha desarrollado ampliamente la tesis de que este es un artículo puente entre el Derecho Internacional de los Derechos Humanos y la Constitución. Este es un asunto pacífico. 
El dilema surge con la vulneración alegada: técnicamente habrá que estimar en cualquier requerimiento que el artículo $5^{\circ}$ de la Constitución está infraccionado como una vía instrumental de un derecho que está fuera de la Constitución, sea que se conecte o no, con un derecho propiamente constitucional.

Este tipo de infracción es el que ha llevado a bifurcar caminos sobre la naturaleza de la norma infringida.

Desde la teoría de las fuentes hay más de alguna vía.

Una de las fórmulas que vertió mucha tinta en las impresoras es la relación jerárquica entre fuentes, siendo supraconstitucional, constitucional, infraconstitucional pero supralegal la posición del tratado de derechos humanos.

Otro recorrido de mayor actualidad, y de fuertes reminiscencias constitucionales francesas, es el bloque de constitucionalidad, que integra contenidos convencionales de derechos fundamentales al parámetro de constitucionalidad, imponiendo una regla jerárquica densa para afrontar un conflicto de derechos.

La vía natural desde el sistema de fuentes son las reglas de incorporación explícitas del tipo artículo primero de la Constitución mexicana o del listado de tratados del artículo X de la Constitución argentina. Modelos claros que enmarcan la regla de reconocimiento constitucional y que advierten las insuficiencias de nuestro artículo $5^{\circ}$ inciso $2^{\circ}$, que un trabajo de reciente data Humberto Nogueira promueve cambiar por la vía de la reforma constitucional (Nogueira Humberto, Las Bases de la Institucionalidad, Librotécnia 2015).

Pero no son las únicas fórmulas; este libro nos deja entrever otros desafíos que vienen en anunciados desde la teoría de la interpretación y no desde las fuentes.

Voy a dejar para el final el Control de Convencionalidad, no sin antes indicar que este modelo es un ejercicio interpretativo por excelencia. Partamos por el principio de interpretación conforme a la Convención y/o a la Constitución. Este es un ejercicio de armonización de derechos, principios y normas contenidos en los tratados respecto de aquellos que son parte integrante de la Constitución. Por ende la interpretación, conforme atiende al contenido y no al continente -propio de la jerarquía- en que se vierten dichos principios, valores y normas.

Este tipo de interpretación avanza en la configuración de estándares. Algo así ya ha recogido la jurisprudencia del Tribunal Constitucional (STC 2492 y 2493) sobre las determinaciones de la Corte Interamericana en casos de restricción de la competencia de la justicia militar, sea para el juzgamiento de personal con fuero militar pero respecto de delitos comunes, como para la afectación por militares de bienes jurídicos de clara connotación de civiles y con víctimas de esta condición.

Otra de las vías que se ha ido extendiendo es aquella en donde el estándar supera la lógica del caso concreto, y es tal su nivel de persuasión que puede estimarse que configura una res interpretata. La cosa interpretada se desprende del caso concreto y del país para el cual fue juzgado y se aplica como una nueva regla que los ordenamientos nacionales pueden adoptar. Tal es el ejemplo, que asumiendo el estándar del Caso Radilla Pacheco con México se utilizó por el TC chileno en casos de justicia militar.

Finalmente, está la dimensión propiamente tal del control de convencionalidad, que asumiendo lo extenso de este comentario ya no da para más que un par de palabras. Hay que seguir esperando de la Corte precisiones doctrinarias. Sin embargo, hay que relevar el énfasis interno que de ella se deduce. Estas definiciones deben hacerse "dentro de las competencias y de las regulaciones procesales correspondientes a cada autoridad". Por tanto, el control de convencionalidad se realiza en el marco de un proceso que 
efectiviza la $\mathrm{CADH}$, pero sin romper con la Constitución de cada país. El orden interno verificará las formas de cumplimiento de esta modalidad de control el que se ha hecho, pero que está muy lejos de constituirse en un ejercicio constante, entre otras cosas, por las ausencias de definiciones internas pendientes.

Si miramos el conjunto de estos desafíos hay cuestiones, a lo largo de este trabajo, que despliega problemas no resueltos en nuestros orden interno. Por último, el libro se despliega en una de las dimensiones normativas más necesarias como áridas. El Derecho Procesal Constitucional, según algunos autores, es una de las grandes aportaciones que el derecho latinoamericano ha desarrollado, aun cuando algunos sitúan en el propio Hans Kelsen el surgimiento de este concepto y otros privilegian en la región el empuje de Eduardo Couture o Héctor Fix - Zamudio. Pues bien, más allá de estas definiciones, este libro da cuenta de un verdadero Derecho Procesal Convencional. Quizás una de las mejores novedades de este trabajo es acentuar la aproximación al conocimiento del conjunto del Sistema Interamericano de Derechos Humanos, sea en su parte dogmática, pero sobre todo, en su parte procedimental. Este esfuerzo es extraordinariamente meritorio porque antes se habían limitado los análisis a los excelentes trabajos, entre otros del propio Claudio Nash sobre la cuestiones de reparación y medidas provisionales. Sin embargo, aquí encontraremos mucho más. Hay análisis pertinentes sobre los procedimientos de admisibilidad ante la Comisión Interamericana, el procedimiento de solución amistosa como el de fondo ante la Corte. En esta etapa las medidas provisionales adquieren una relevancia extraordinaria y compleja. En las etapas ante la propia Corte se estudian sus competencias contenciosas y consultivas. Particular relevancia adquiere las decisiones que involucran reparaciones. La dimensión de la responsabilidad de los Estados, si bien trasuntan reparaciones en dinero, también abarcan dimensiones simbólicas, normativas y procesales que prefiguran una propia materia sobre la cual los propios ordenamientos tienen muchas falencias.

En suma, se trata de un libro extraordinario, que costará mucho superarlo, que constituye una obligación para los operadores jurídicos trabajar con él y que para los expertos es una gran guía para llegar al material de fondo y de jurisprudencia que permite satisfacer sus necesidades jurisprudenciales o investigativas. Si el TEDH ha citado en más de 25 sentencias esta jurisprudencia es por algo, por su autoridad, y ella se despliega con rotundidad en este libro. Larga vida a este libro, a sus autores y a la Fundación. 